\title{
Air conditioning in the region of Madrid, Spain: An approach to electricity consumption, economics and $\mathrm{CO}_{2}$ emissions
}

\author{
M. Izquierdo ${ }^{\mathrm{a}, \mathrm{b}}, *$, A. Moreno-Rodríguez ${ }^{\mathrm{a}}, \mathrm{A}$. González-Gil ${ }^{\mathrm{b}}$, N. García-Hernando ${ }^{\mathrm{a}}$ \\ ${ }^{a}$ Escuela Politécnica Superior, Universidad Carlos III de Madrid, Avenida de la Universidad 30, 28911, Leganés, Madrid, Spain \\ ${ }^{\mathrm{b}}$ Instituto de Ciencias de la Construcción Eduardo Torroja (CSIC), c/Serrano Galvache 4, 28033 Madrid, Spain
}

\begin{abstract}
A B S T R A C T
An understanding of electricity consumption due to residential air conditioning (AC) may improve production and environmental impact strategy design. This article reports on a study of peak and seasonal electricity consumption for residential air conditioning in the region of Madrid, Spain. Consumption was assessed by simulating the operation of AC units at the outdoor summer temperature characteristics of central Spain. AC unit performance when operating under part load conditions in keeping with weather conditions was also studied to find cooling demand and energy efficiency. Like wise final electricity consumption was computed and used to calculate energy costs and greenhouse gas emissions (GHGs). Cooling demand, when family holidays outside the region were factored into the calculations, came to $1.46 \times 10^{9} \mathrm{kWh}$. Associated seasonal electricity demand was $617 \times 10^{6} \mathrm{kWh}$ and seasonal performance of $A C$ units around 2.4. Electricity consumption in the whole region was observed to peak on 30 June 2008 at $5.44 \times 10^{6} \mathrm{~kW}$, being the load attributable to residential AC $1.79 \times 10^{6} \mathrm{~kW}$, resulting about $33 \%$ of the total peak consumption. The seasonal cost per household was about $€ 156$ and the total equivalent warming impact was $572 \times 10^{3} \mathrm{tCO}_{2}$. The method proposed can be adapted for use in other regions.
\end{abstract}

\section{Introduction}

Greenhouse gas emissions (GHGs) resulting from electric power generation have risen sharply in Spain in the last 12 years. According to the Spanish Ministry of the Environment's GHG inventory [1], total equivalent warming impact emissions grew from 250 million to 380 million tonnes, i.e., by $149.5 \%$ between 1996 and 2006.

However, as a result of lower demand due to the economic crisis and the increase in the amount of electricity produced in combined cycle (around 30\% of the total) and renewable energy plants, between 2007 and 2009 emissions declined by around $10 \%$, to 350 million tonnes of $\mathrm{CO}_{2}$. Spanish emissions per capita in 2009 came to $9.5 \mathrm{t}$.

A population's consumption of electricity is associated with its standard of living. But it is well known that such consumption has adverse consequences for the Earth's environment. Ensuring the supply of electricity and environmental quality is the responsibility

\footnotetext{
* Corresponding author. Unidad Asociada de Ingeniería de Sistemas Energéticos UC3M-CSIC, Spain. Tel./fax: +34 918713248.

E-mail address: mizquierdo@ietcc.csic.es (M. Izquierdo).
}

of public authorities. Therefore, their objective is to implement efficient energy models that also ensure excellent air quality as stated in the Community of Madrid's Energy Plan, 2004-2012 [2].

In high temperature climates, residential sector air conditioning (AC) generates power needs that these authorities prefer not to leave unmet. Moreover, as a recent report about the Spanish elec tric system shows [3], temperature extremes concur with yearly peak demand or peak consumption. This fact, which represents a serious problem for the stability and reliability of electricity distribution systems, was also observed in [4]. In such interesting study it was concluded that temperature is one of the most important factors affecting the electricity demand of a population. Knowing the actual energy consumption generated directly by AC may therefore help policy makers plan power generation and environmental impact strategies.

The region of Madrid, where this study was conducted in 2009, is a densely populated area with around 2.3 million primary resi dences and a population of 6.2 million, i.e., a mean of over three occupants per household, according to the Spanish National Statistics Institute, [5]. The region's gross domestic product per capita is $133 \%$ of the national mean and slightly higher than the European average. Energy consumption per inhabitant is $1.8 \mathrm{t}$ of oil 


\begin{tabular}{|c|c|c|c|}
\hline \multicolumn{2}{|c|}{ Nomenclature } & \multirow{2}{*}{$\begin{array}{l}\text { aux } \\
c \\
\text { cd }\end{array}$} & \multirow{2}{*}{$\begin{array}{l}\text { ancillary } \\
\text { compressor } \\
\text { condensation }\end{array}$} \\
\hline$A$ & area $\left(\mathrm{m}^{2}\right)$ & & \\
\hline$A C$ & air conditioning & \multirow{2}{*}{$\begin{array}{l}\text { com } \\
\text { d }\end{array}$} & commercial \\
\hline COP & coefficient of performance & & design \\
\hline $\mathrm{cp}$ & specific heat $\left(\mathrm{kJ} \mathrm{kg}^{-1} \mathrm{~K}^{-1}\right)$ & ed & expansion device \\
\hline$D$ & demand $(\mathrm{kWh})$ & eq & household equipment \\
\hline$f$ & leakage rate & el & electric \\
\hline$h$ & enthalpy $\left(\mathrm{kJ} \mathrm{kg}^{-1}\right)$ & ev & evaporation \\
\hline 1.r. & load rate (\%) & fc & constant flow \\
\hline$M$ & mass $(\mathrm{kg})$ & fv & variable flow \\
\hline$m$ & mass flow rate $\left(\mathrm{kg} \mathrm{s}^{-1}\right)$ & $\mathrm{G}$ & global \\
\hline$N$ & number & $\mathrm{gl}$ & glazing \\
\hline$Q$ & thermal load (kW) & $\mathrm{i}$ & time interval \\
\hline$q$ & heat per unit of mass $\left(\mathrm{kJ} \mathrm{kg}^{-1}\right) /$ person/area & il & illumination \\
\hline$R$ & solar gain $\left(\mathrm{kW} \mathrm{m}^{-2}\right)$ & in & indoor \\
\hline$T$ & dry bulb temperature $\left({ }^{\circ} \mathrm{C}\right)$ & inf & infiltration \\
\hline$U$ & global transmission coefficient $\left(\mathrm{kW} \mathrm{m}^{-2} \mathrm{~K}^{-1}\right)$ & is & isentropic \\
\hline$V$ & volume $\left(\mathrm{m}^{3}\right)$ & $\max$ & maximum \\
\hline$W$ & power consumption $(\mathrm{kW})$ & me & mechanical \\
\hline$w$ & work per unit of mass $\left(\mathrm{kJ} \mathrm{kg}^{-1}\right)$ & $\min$ & minimum \\
\hline$Y$ & number of years & out & outdoor \\
\hline & & \multirow{2}{*}{$\begin{array}{l}\mathrm{p} \\
\mathrm{pl}\end{array}$} & person \\
\hline Gree & ters & & part load \\
\hline$v$ & specific volume $\left(\mathrm{m}^{3} \mathrm{~kg}^{-1}\right)$ & $\mathrm{r}$ & refrigerant \\
\hline$\eta$ & efficiency & rd & radiation \\
\hline$\Delta$ & increment & rv & reversible \\
\hline & & $\mathrm{t}$ & transmission \\
\hline Subs & & th & thermal \\
\hline a & air & \multirow[t]{2}{*}{$\mathrm{w}$} & wall, ceiling, floor \\
\hline ae & air exchanges & & \\
\hline
\end{tabular}

equivalent (TOE), compared to 2.5 TOE in the European Union. The region's energy related $\mathrm{CO}_{2}$ per capita, at $6.1 \mathrm{t}$, is much lower than the European mean of $8.2 \mathrm{t}$. The transport industry at $51 \%$, the residential and commercial sector at $24.5 \%$, and manufacturing at $12 \%$, account for the largest share of final energy consumption. Ten percent goes to the service sector and just under $2 \%$ to farming. The energy sources include petroleum derivatives, which cover $62 \%$ of the demand, electric power, $21 \%$, natural gas, $15 \%$ and other sources nearly $2 \%[2]$.

To the authors' knowledge, no data have been published on electricity consumption by or the resulting TEWI attributable to residential AC units in the region of Madrid. The present study aimed to assess both as accurately as possible.

The only technical information available for buyers of AC units is contained in the user's instructions booklet furnished with the facility, which includes the manufacturer's power consumption and energy efficiency estimates. This information does not suffice, however, to evaluate the power consumed or the emissions generated by $\mathrm{AC}$ units.

A second aim of the present study, then, was to compare elec tricity consumption and $\mathrm{CO}_{2}$ emissions, found using manufacturer's specifications, to the consumption and emission values obtained with a numerical simulation based on the refrigerant cycle. In the present study, a simulation was run based on outdoor summertime temperature characteristics of the area. Assumptions were made with respect to the standard building envelope and the location and total number of $\mathrm{AC}$ units installed in the region. Coefficient of performance (COP) was determined by applying energy balances to the refrigeration cycle in terms of isentropic, mechanical and electrical efficiency. Part load operation and the electricity con sumed by auxiliary elements were also taken into consideration.
Other results of interest, such as the comparison between elec tricity consumption obtained from the simulation and manufac turer's specifications, were also recorded. Furthermore, taking into account real information on electric power consumption in the region of Madrid furnished by Iberdrola Distribución, S.A.U [6], the influence of cooling demand on the electricity peak consumption was obtained.

\section{Methodology}

The methodology followed to meet the paper's aims is discussed in this section. To begin with, information about number of dwellings and population of Madrid, Spanish standard dwelling size and construction materials, and the amount of air conditioned homes are taken from the Spanish National Statistics Institute [5].

Next, by using meteorological data from the weather station of the Eduardo Torroja Institute's Solar Energy Experimental Plant at Arganda del Rey, $22 \mathrm{~km}$ far from Madrid, seasonal thermal demand is calculated taking into account the effect of family holidays outside the region (Section 4). This will represent one of the first results of the present research. To the knowledge of the authors, no similar assessment had been performed before for the region of Madrid.

Once known the cooling demand, it is necessary to determine the seasonal COP and the electricity consumed by the AC systems. For that, a numerical simulation was carried out based on the air cooled vapour mechanical compression cycle for refrigerant R410A (Section 5). Data from Spanish AC manufacturers' association are used to conclude that this is the most commonly used refrigerant in domestic AC. With the aim of making the presentation of simula tion results more clear, three representative summer days were selected. Likewise, seasonal results are shown and compared with 
experimentally validated data from AC manufacturers' technical catalogs and official Spanish regulations.

In order to assess the difference between using simulation results and data given by manufacturers to AC users, the perfor mance of two different commercial units suitable for Spanish standard dwelling is analyzed in Section 6. In this analysis, real weather conditions of the region are taken into account.

With those results and by using real information on electric power consumption furnished by the main distribution utility in the region of Madrid, contribution of residential AC systems to total and peak electricity consumption is assessed in Section 7. As well, economical cost for AC users is estimated. Finally, in Section 8, the environmental impact associated to electricity consumption of AC systems in the region is calculated in terms of equivalent $\mathrm{CO}_{2}$ emissions.

Conclusions drawn from this study will be used in the following work to compare electric AC systems with air cooled $\mathrm{LiBr}-\mathrm{H}_{2} \mathrm{O}$ absorption prototypes, developed by our research group under INVISO SP3 and ENE2010 20650 C02 01 projects. The final objec tive of this research is to substitute mechanical compression chi llers by absorption ones in order to reduce electricity consumption peaks and $\mathrm{CO}_{2}$ emissions.

\section{Starting data}

\subsection{Standard air conditioned home}

According to the Spanish National Statistics Institute [5], the mean net size of Spanish homes is $80 \mathrm{~m}^{2}$ and the distance between structural floor and ceiling slabs is usually $2.5 \mathrm{~m}$. Not all rooms are air conditioned; units are generally installed in the living dining room and bedrooms, which account for around $60 \%$ of the total area. The standard home chosen for the present study was assumed to be oriented north-south, located at mid height in the building and occupied by three people. The standard envelope consists of:
$1 / 2$ foot facing brick;
$4 \mathrm{~cm}$ of glass wool insulation;
$4 \mathrm{~cm}$ hollow brick;
$1.5 \mathrm{~cm}$ of rough plaster; and
double glazed windows ( $15 \%$ surface).

For the purposes of the simulation, all homes were assumed to have the same characteristics, in the awareness that any such assumption involves some degree of error.

\subsection{Units installed}

The number of units installed was determined on the grounds of statistical information from the latest census (2001) [5], according to which $21.3 \%$ of the $1,873,671$ primary residences existing in the region at the time were air conditioned. In the interim another 450,000 primary residences have been built according to the Ministry of Housing [7]. In light of the high quality of these homes and user demands, most may be assumed to be air conditioned. Therefore, for a primary residence park in 2008 of 2,235,000, the number of AC units installed was around 850,000 , from which it may be deduced that around $38 \%$ of all homes had AC.

\subsection{Outdoor temperature}

The outdoor dry bulb temperature was obtained from the weather station on site at the Eduardo Torroja Institute's Solar Energy Experimental Plant at Arganda del Rey (southeast Madrid), where six readings are taken per hour. Fig. 1 shows the high and low temperatures in the four summer months, from June to September,

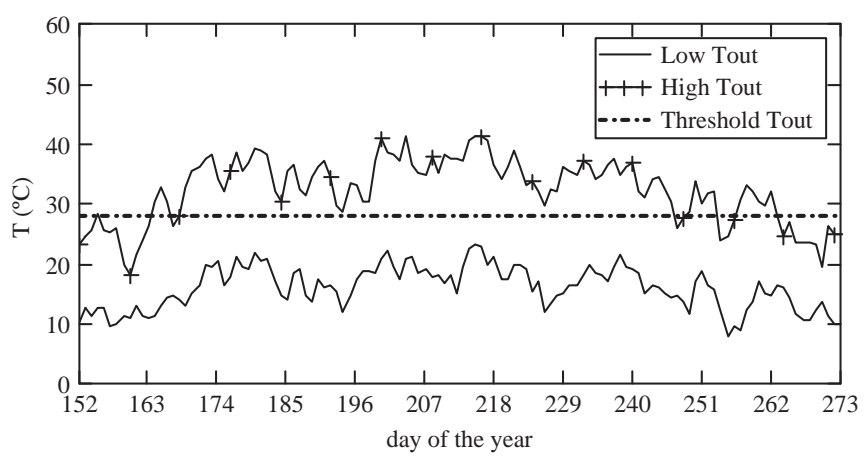

Fig. 1. High, low and threshold outdoor temperatures in the summer of 2008.

in 2008. Note the approximately constant difference between the two. The absolute high, $41.5^{\circ} \mathrm{C}$, was recorded on 4 August (day 216) and the absolute low, $8^{\circ} \mathrm{C}$, on 12 September (day 255).

Fig. 2 shows the daily variations in outdoor temperatures on three representative days in the $\mathrm{AC}$ season. Note that the curves are nearly parallel, with highs of around $40^{\circ} \mathrm{C}$ (2 August), $35^{\circ} \mathrm{C}(11$ July) and $30^{\circ} \mathrm{C}$ (13 June). A study conducted by Izquierdo et al. [8] reported similar findings. The indoor dry bulb temperature, pur suant to the Spanish Regulations on Thermal Facilities in Buildings [9], was assumed to be $25^{\circ} \mathrm{C}$.

AC was assumed to come on when the outdoor temperature reached $28^{\circ} \mathrm{C}$, the threshold for the intents and purposes of the present study.

\section{Thermal load and demand}

The first step in AC design is to calculate cooling load, which has a significant effect on AC unit efficiency. Thermal load depends on:

1 heat transfer coefficient of the building envelope;

2 weather conditions;

3 internal loads; and

4 external loads.

\subsection{Heat transfer through the building envelope}

Variables for walls, ceilings and floors were used to obtain the heat transfer coefficient, $\Sigma\left(U_{\mathrm{w}} A_{\mathrm{w}}\right)$, for the envelope applied in Eq. (1) to find thermal load transfer. The design temperature, $41.5^{\circ} \mathrm{C}$, Eq. (2), was chosen because it is only exceeded in $0.01 \%$ of the summertime.

$Q_{\mathrm{t}} \quad\left[\sum\left(U_{\mathrm{w}} A_{\mathrm{w}}\right) \cdot \Delta T_{\mathrm{d}}\right]$

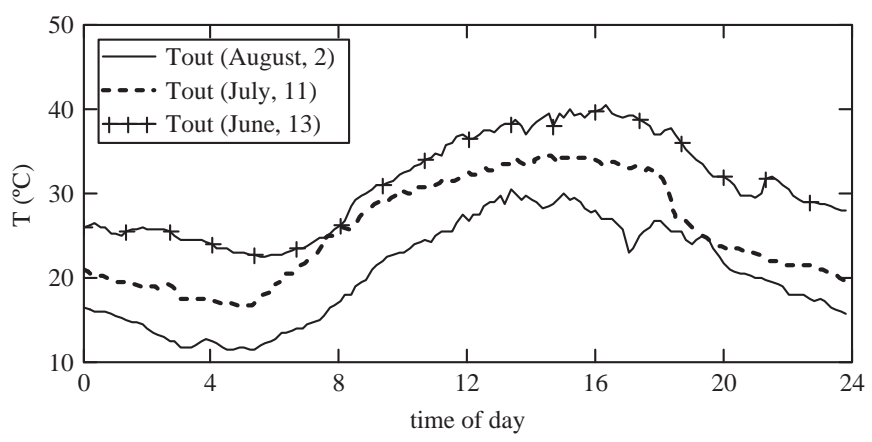

Fig. 2. Outdoor temperatures in three representative summer days of 2008 . 
$\Delta T_{\mathrm{d}} \quad T_{\mathrm{d}} \quad 25$

\subsection{Internal and external loads}

Other thermal load exchanges take place between the indoor and outdoor environments, as a result of ventilation $\left(Q_{\mathrm{ae}}\right)$, including infiltration $\left(Q_{\mathrm{inf}}\right)$, radiation through openings or windows $\left(Q_{\mathrm{rd}}\right)$, occupancy in interiors $\left(Q_{\mathrm{p}}\right)$ and lighting $\left(Q_{\mathrm{il}}\right)$ and other household appliances $\left(Q_{e q}\right)$. The calculation of these loads, Eqs. (3)-(7), was based on Pizzeti [10] and ASHRAE [11] and according to Spanish Regulations $[9,12]$.

$\begin{array}{ll}Q_{\mathrm{as}} & N_{\mathrm{as}} \cdot V_{\mathrm{in}} \\ Q_{\mathrm{inf}} & \frac{v_{\mathrm{a}}}{\mathrm{v}} \cdot \mathrm{cp} \cdot \Delta T_{\mathrm{d}} \\ Q_{\mathrm{rd}} & A_{\mathrm{gl}} \cdot R \\ Q_{\mathrm{p}} & N_{\mathrm{p}} \cdot q_{\mathrm{p}} \\ Q_{\mathrm{il}} & A_{\mathrm{il}} \cdot q_{\mathrm{il}}\end{array}$

4.3. Thermal load and global heat transfer coefficient for the envelope

A home's design thermal load can be determined from Eq. (8), which represents the sum of every load mentioned above.

$Q_{\mathrm{d}} \quad Q_{\mathrm{t}}+Q_{\mathrm{inf}}+Q_{\mathrm{rd}}+Q_{\mathrm{p}}+Q_{\mathrm{il}}+Q_{\mathrm{eq}}$

The global transfer coefficient for the envelope is defined in Eq. (9). This value, which includes all the thermal load exchanges in the home, is a useful simplification for simulating instantaneous load according to Eq. (10).

$(U \cdot A)_{\mathrm{G}} \quad \frac{Q_{\mathrm{d}}}{\Delta T_{\mathrm{d}}}$

$Q_{i} \quad(U \cdot A)_{\mathrm{G}} \cdot \Delta T_{\mathrm{i}}$

The obtained value for $(U \cdot A)_{\mathrm{G}}$ resulted to be $0.35 \mathrm{~kW} /{ }^{\circ} \mathrm{C}$.

\subsection{Daily and seasonal thermal demand}

The daily thermal load shown in Fig. 3 was found by applying Eqs. (1)-(10) to the temperatures for the three representative summer days shown in Fig. 2. The peak observed for 2 August, $5 \mathrm{~kW}$, was reached between 3:00 and 5:00 p.m.; on 11 July, the 3 kW maximum appeared between 2:00 and 4:00 p.m., and on 13 June load peaked at $2 \mathrm{~kW}$ between 1:00 and 3:00 p.m.

The daily cooling demand was calculated by integrating Eq. (10). The thermal demand for the three representative days was $51.9 \mathrm{kWh}, 24.5 \mathrm{kWh}$ and $4.9 \mathrm{kWh}$ on 2 August, 11 July and 13 June, respectively. When integrating for the whole summer period Fig. 4 is obtained. As shown, the maximum daily thermal demand during the summer, $55.5 \mathrm{kWh}$, was observed on 4 August. It is also seen from Fig. 4 that cooling period extended from 12 June to 19 September 2008, being the seasonal thermal demand $2178 \mathrm{kWh}$.

Expanding the calculation to include all the dwellings in the region with $A C$ units installed yielded the demand distribution shown in Fig. 5 for the summer of 2008.

When all homes were assumed to be occupied, the peak value was observed on days 200 (18 July) and 217 (4 August), when demand came to $4.7 \times 10^{7} \mathrm{kWh} /$ day. To obtain a more realistic

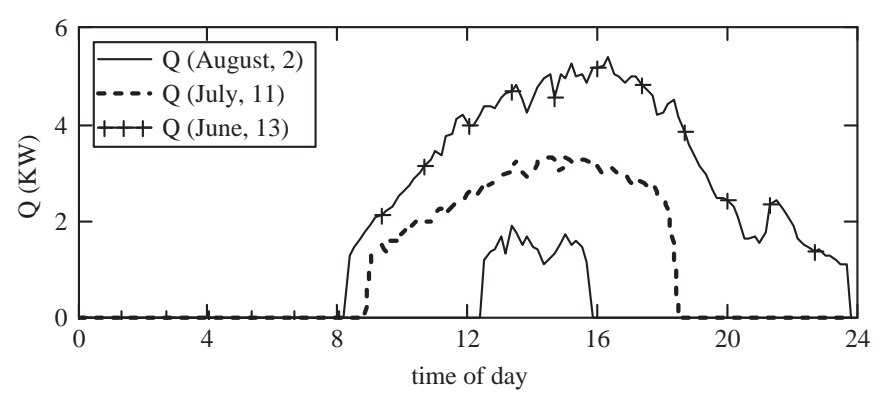

Fig. 3. Thermal load on three representative days (2008).

estimate, however, provision was made for the fact that Madrile nians holiday preferably in the summertime, when a substantial percentage of the population travels to the south or east coasts, inland domestic destinations or abroad. According to data pub lished by the Municipal Government of Madrid [13], 58\% of the capital's population spent their holidays outside the city in 2008. Five percent left in June, 22\% in July, 27\% in August and 4\% in September. The mean duration of these holidays was 21 days. Assuming that these information is valid for the whole region, the final demand in the summer of 2008 was assessed, Fig. 6 . Since the largest number of Madrilenians left the city in August, the demand peak observed on 4 August was slightly smaller than the peak recorded in July. Seasonal demand came to $1.46 \times 10^{9} \mathrm{kWh}$, for a daily mean of $14.6 \times 10^{6} \mathrm{kWh}$, i.e., $39 \%$ of the peak value.

\section{Refrigeration cycle and energy efficiency}

\subsection{Refrigeration cycle}

For the analysis of AC energy efficiency discussed below, units were studied by capacity and type of refrigerant. Another simpli fying assumption made to calculate operating parameters was that all units were fitted with low capacity (up to $7 \mathrm{~kW}$ ), electrically powered, air cooled, mechanical compression chillers.

The information needed on the type of refrigerant used was drawn from the statistics published by the national manufacturers' association on the number of units installed in recent years and the refrigerant used [14]. Prior to and including 2004, the units installed used R22, but subsequently they were replaced by units working with R407C refrigerant. Some R22 units were still installed in 2005, but most carried R407C. AC units operating with R410A began to be installed in 2005 to replace chillers charged with R407C and R22. From 2006 onward, the refrigerant in most air condi tioners installed was R410A.

Inasmuch as all the units installed prior to 2004 used R22 and that given the scant success of R407C most air conditioners installed between that year and 2008 carried R410A, the AC park was assumed to consist of machines with two refrigerants only, R22 and R410A. Despite the differences in the mechanical and ther modynamic characteristics of these two refrigerants, since more

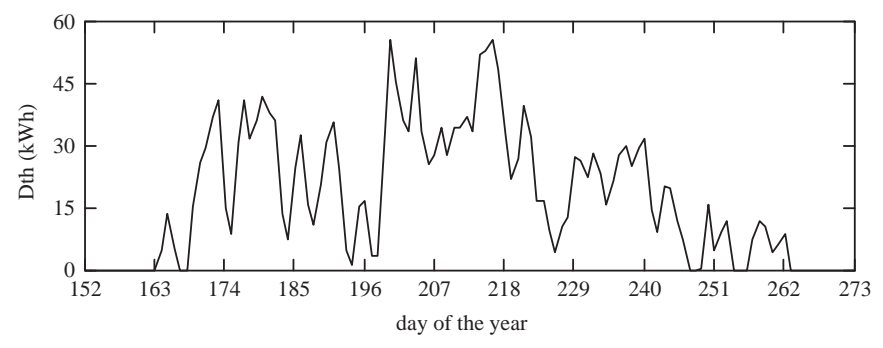

Fig. 4. Seasonal thermal demand per home (2008). 


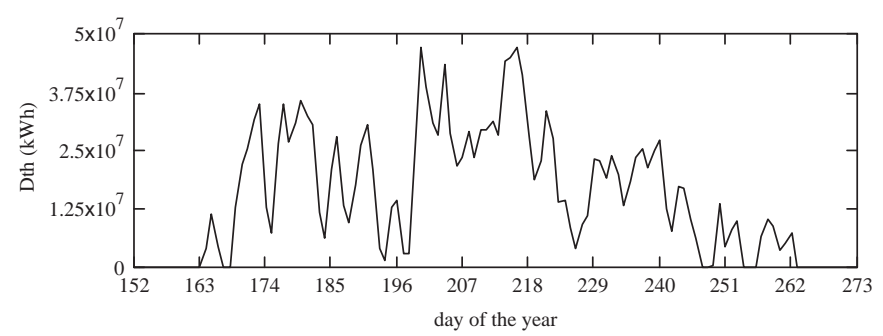

Fig. 5. Thermal demand for air conditioning $(A C)$ in the entire housing park in the Madrid region (2008).

R410A than R22 units were in place in 2008 , the air cooled vapour mechanical compression cycle for the former was used in these calculations.

Fig. 7 shows the refrigeration cycle for R410A. The energy balance was found for the main components of the refrigeration cycle.

\subsubsection{Evaporator}

According to $\mathrm{Yu}$ and Chan [15] the evaporating temperature is supposed to vary in a range of between 3 and $5{ }^{\circ} \mathrm{C}$ over the whole range of load conditions. Furthermore, following manufacturer recommendations, the outflowing refrigerant was assumed to be superheated by $5{ }^{\circ} \mathrm{C}$. The refrigeration capacity required to meet demand, $Q_{e v}$, was obtained from Eq. (11), which disregards exchanger losses. The change in specific enthalpy, $q_{\mathrm{ev}}$, was found with Eq. (12), which yielded the enthalpy values shown in Fig. 7. The refrigerant flow rate, $\dot{m}_{r}$ according to Eq. (12), is the ratio between the refrigeration capacity and the change in specific enthalpy in the evaporator.

$Q_{\mathrm{ev}} \quad \dot{m}_{\mathrm{r}} h_{1} \quad \dot{m}_{\mathrm{r}} h_{4} \quad 0$

$\frac{Q_{\mathrm{ev}}}{\dot{m}_{\mathrm{r}}} \quad q_{\mathrm{ev}} \quad h_{1} \quad h_{4}$

\subsubsection{Condenser}

Similar reasoning was deployed to write Eq. (13) for the condenser (process 2s-3). In this case, following Pizzeti [10] the condensing temperature, influenced by outdoor temperature, is assumed to be $15{ }^{\circ} \mathrm{C}$ over it. Besides, pursuant to manufacturer design conditions, the enthalpy value at the condenser outlet, $h_{3}$, was assumed to include a sub cooling value of $5^{\circ} \mathrm{C}$.

$\frac{Q_{\mathrm{cd}-\mathrm{rv}}}{\dot{m}_{\mathrm{r}}} \quad q_{\mathrm{cd}-\mathrm{rv}} \quad h_{2 \mathrm{~s}} \quad h_{3}$

\subsubsection{Expansion device} (14):

Process $3-4$ is assumed to be isenthalpic and according to Eq.

$\left(\begin{array}{ll}h_{3} & h_{4}\end{array}\right) \cdot \dot{m}_{\mathrm{r}} \quad Q_{\mathrm{sd}} \quad 0$

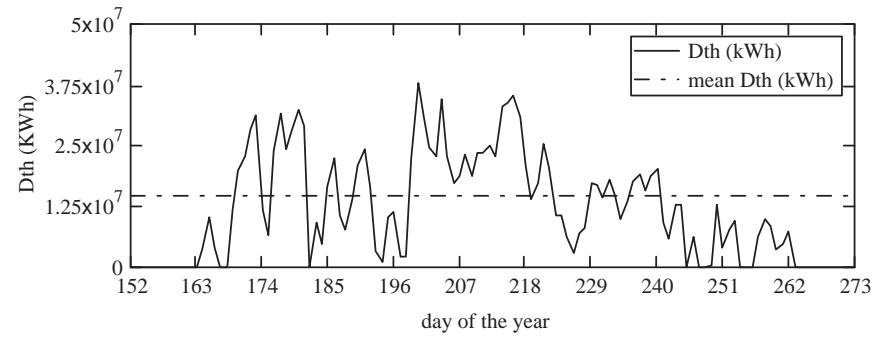

Fig. 6. AC thermal demand in the region of Madrid in 2008.

\subsubsection{Compressor}

A reversible change in specific enthalpy, $w_{\mathrm{c}-\mathrm{rv}}$ (process $1-2 \mathrm{~s}$ ) is observed in the compressor as per Eq. (15), which permits us to obtain the reversible work $W_{\mathrm{c} \text {-rv. }}$.

$\frac{w_{\mathrm{c}-\mathrm{rv}}}{\dot{m}_{\mathrm{r}}} \quad w_{\mathrm{c}-\mathrm{rv}} \quad h_{2 \mathrm{~s}} \quad h_{1}$

The work performed involved a reversible cycle. According to Bernier [16], however, isentropic efficiency must be taken into account when considering irreversible steps in the refrigerant compression process. Eq (16) shows that isentropic efficiency, $\eta_{\text {is, }}$ is defined as the ratio between reversible and isentropic work.

$W_{\mathrm{c}-\mathrm{is}} \quad \frac{w_{\mathrm{c}-\mathrm{rv}}}{\eta_{\mathrm{is}}}$

If account is also taken of the rest of the components that drive the compressor, efficiency at its axis, $\eta_{\text {me, }}$, must be considered, [16]. Eq. (17) indicates that mechanical work can be found as the result of applying mechanical efficiency to isentropic power consumption.

$W_{\mathrm{c}-\mathrm{me}} \quad \frac{w_{\mathrm{c}-\mathrm{is}}}{\eta_{\mathrm{me}}}$

For electrically powered compressors, another efficiency value, electric efficiency, $\eta_{\mathrm{el}}$, is required according to Bernier [16]. In this case, $\eta_{\mathrm{el}}$ represents the ratio between mechanical and electrical work, Eq. (18).

$W_{\mathrm{c}-\mathrm{el}} \quad \frac{w_{\mathrm{c}-\mathrm{me}}}{\eta_{\mathrm{el}}}$

The values for $\eta_{\text {me }}$ and $\eta_{\mathrm{el}}$ can be assumed to be constant according to Chen et al. [17] and Qureshi and Tassou [18].

\section{2. $C O P$}

In reversible processes, $\mathrm{COP}\left(\mathrm{COP}_{\mathrm{c}-\mathrm{rv}}\right)$ is defined to be the ratio between the heat transferred in the evaporator (Eq. (12)) and the equivalent value in power absorbed by the compressor (Eq. (15)).

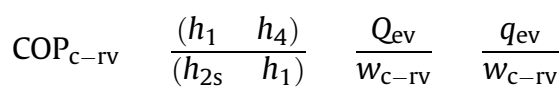

On the other hand, isentropic $\mathrm{COP}\left(\mathrm{COP}_{\mathrm{c}-\mathrm{is}}\right)$ is obtained by applying the isentropic efficiency to Eq. (19).

$\mathrm{COP}_{\mathrm{c}-\mathrm{is}} \quad \mathrm{COP}_{\mathrm{c}-\mathrm{rv}} \cdot \eta_{\mathrm{is}}$

Mechanical performance can be found with Eq. (21), and elec trical performance with Eq. (22). Lastly, all the irreversible processes taking place in the compressor, as well as ancillary element power consumption are factored into Eq. (23) to yield the performance for the unit. Likewise, Eq. (24) is used to obtain the power consumption for the unit when operating at constant flow.

$\mathrm{COP}_{\mathrm{c}-\mathrm{me}} \quad \mathrm{COP}_{\mathrm{c}-\mathrm{rv}} \cdot \eta_{\text {is }} \cdot \eta_{\mathrm{me}}$

$\mathrm{COP}_{\mathrm{c}-\mathrm{el}} \quad \mathrm{COP}_{\mathrm{c}-\mathrm{rv}} \cdot \eta_{\mathrm{is}} \cdot \eta_{\mathrm{ms}} \cdot \eta_{\mathrm{el}}$

$\mathrm{COP}_{\mathrm{fc}} \frac{Q_{\mathrm{ev}}}{w_{\mathrm{c}-\mathrm{el}}+w_{\mathrm{aux}}}$

$W_{\mathrm{fc}} \quad w_{\mathrm{c}-\mathrm{el}}+w_{\mathrm{aux}}$

\subsection{Part load efficiency}

AC units are able to adapt their capacity to cooling demand by working under part load conditions. As a result, their efficiency may 


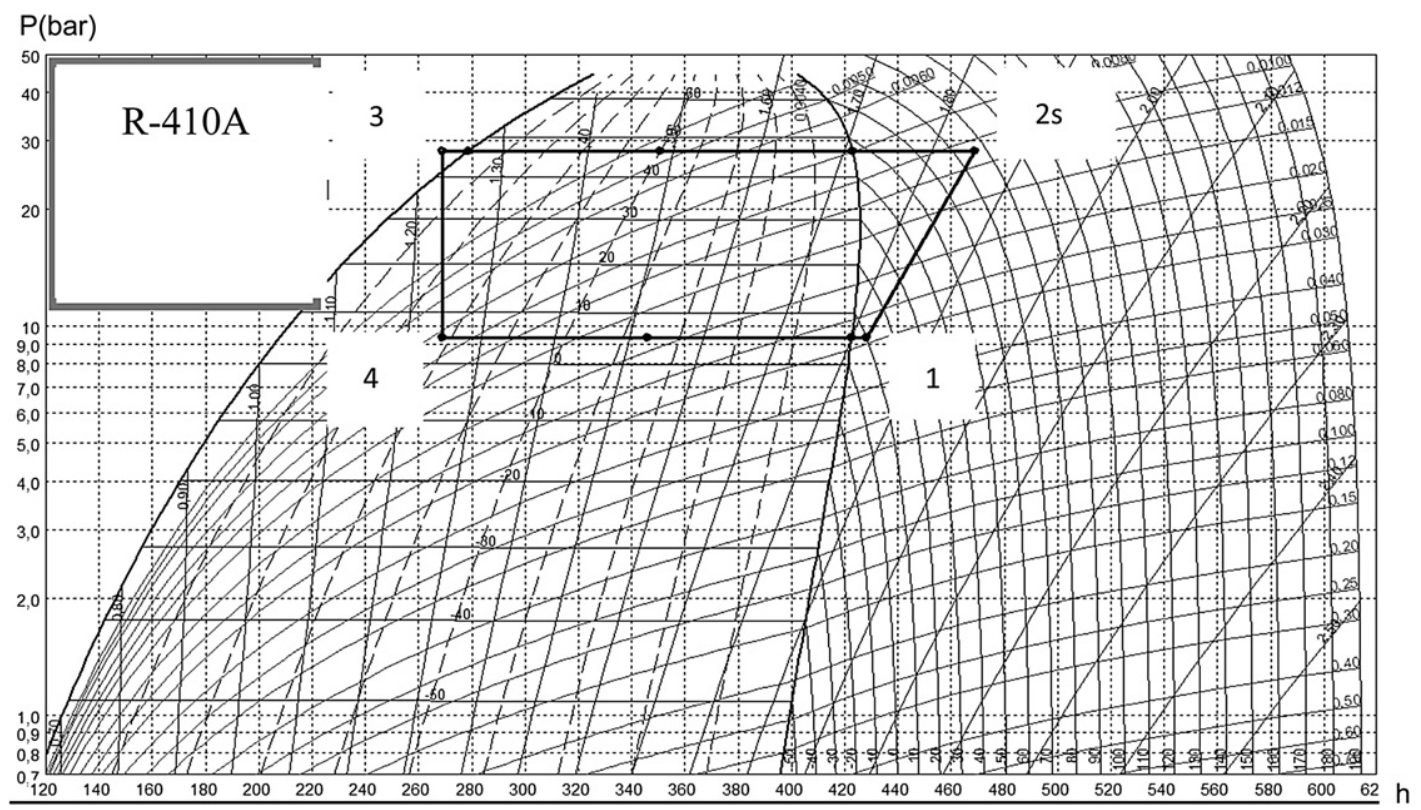

Fig. 7. Pressure enthalpy diagram $\mathrm{kj} / \mathrm{kg}$ for the R410A refrigeration cycle (Solkane software).

be considerably different from that one corresponding to full load, as analyzed by Yu and Chan [15]. The part load efficiency depends on the load rate (1.r.), which can be defined as the thermal capacity transferred by an AC unit with respect to its nominal capacity.

Fig. 8 shows the condition line for a single home, which defines the thermal load for the studied home and the capacity curve for a hypothetical AC unit operating at its nominal load rate. The unit could accommodate thermal load up to an outdoor temperature close to the summertime maximum, where the two curves intersect.

Variable speed control of compressors is probably the most used method to regulate the capacity air conditioners. Moreover, according to Shuangquan Shao et al [19], it is one of the best options of regulation. A number of authors have conducted experimental studies on variable flow compressor efficiency, such us Tassou and Qureshi with reciprocating compressors in refrigeration facilities [20], or Aprea et al. with scroll compressors [21]. For the purpose of this study, it is supposed that the AC units have variable speed regulation, being the efficiency due to part load operation defined by $\mathrm{Eq},(25)$. COP $\mathrm{fv}$ represents the overall COP considering the effect of variable flow regulation.

$\eta_{\mathrm{pl}} \frac{\mathrm{COP}_{\mathrm{fv}}}{\mathrm{COP}_{\mathrm{fc}}}$

Thus, power consumption for the variable flow compressor can be found with Eq. (26).

$W_{\mathrm{fv}} \quad W_{\mathrm{fc}} \cdot \eta_{\mathrm{pl}}$

\subsection{Simulation procedure}

Simulation is based on the refrigeration cycle analysis, adapting the formulation proposed by Bernier [16] to thermodynamic properties of refrigerant R410A. Eqs. (11)-(26) were implemented in a Mathcad program that enables to simulate the thermodynamic cycle. Taking an hour as simulation time step and using data of thermal load and outdoor temperature from previous steps (Sections 3 and 4), the program simulates the behavior of each component. For every day with cooling demand during the summertime, electricity consumption and COP values are hourly calculated. Both daily electricity consumption and daily COP are obtained by extending this process to all hours with cooling demand in the day. When taking into account the whole period of cooling, seasonal values for electricity consumption and COP are determined. Note that if there is not cooling demand, the AC system is supposed to be turn of, i.e. there is no energy consumption. All these parameters are firstly calculated considering reversible conditions in the compressor, Eqs. (11)-(15). Then, irreversibilities are included by using isentropic, mechanical and electric efficien cies, as defined in Eqs. (16)-(18). Next step consists of adding the electricity consumption of ancillary equipment, such as evaporator or condenser fans, Eqs. (23) and (24). Lastly, the effect of partial load is included according to Eqs. (25) and (26).

This simulation process enables to determine hourly, daily and seasonal COP for a standard AC system in Madrid. As well, it permits to calculate the corresponding electricity consumptions. From these simulation results, it will be possible to assess the environ mental impact and the economical cost associated to AC systems operation in the region of Madrid.

\subsection{Seasonal performance: simulation results}

Figs. 9-11 show the COP for the three representative days. The different COPs defined above are represented. Note that part load efficiency was of minor importance when the unit was operating at around $39^{\circ} \mathrm{C}$, the temperature at which its load rate was close to $100 \%$.

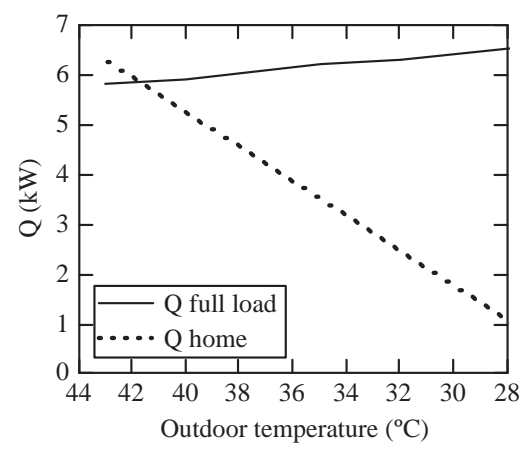

Fig. 8. Thermal load and cooling capacity. 


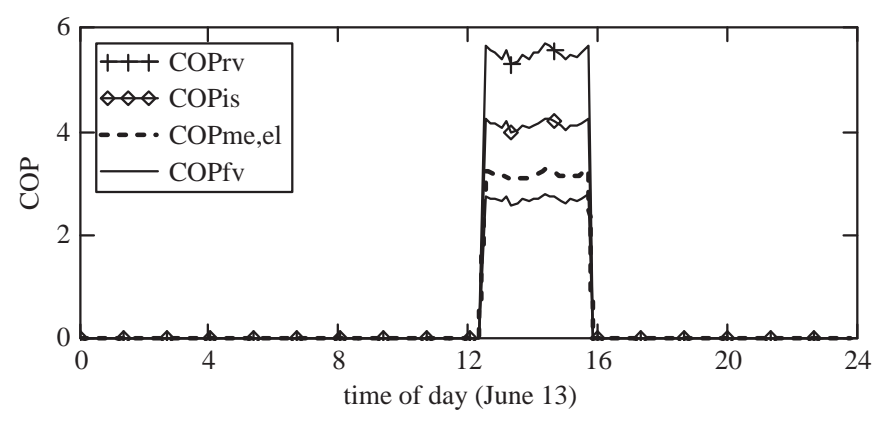

Fig. 9. Coefficients of performance on 13 June.

Fig. 12 shows the daily COP for every summer day. As observed, the seasonal $\mathrm{COP}\left(\mathrm{COP}_{\text {seasonal }}\right)$ resulted to be 2.4 , which is compa rable to the seasonal efficiency values found in the literature. Spain's statutory Regulation for Thermal Facilities in Buildings [9] authorises a COP of 2.6 for small air cooled chillers with recipro cating compressors using refrigerant R22. In addition, the DAN FOSS, S.A. catalogue of compressors [22] specifies a COP of $2.7 \pm 5 \%$ under nominal conditions and evaporation and condensation temperatures typical of Madrid, i.e., $5^{\circ} \mathrm{C}$ and $50{ }^{\circ} \mathrm{C}$, respectively. However, this efficiency value excludes electric power consump tion by ancillary elements as well as operation under partial loads.

In light of the foregoing, the COP of 2.4 found was regarded to be sufficiently accurate for use in the present study.

\section{Performance of commercial AC units}

This section discusses the main operating parameters and curves for the units presently used in residential AC. Two models applying variable flow technology were chosen.

The efficiency curves for two AC units marketed by a well known manufacturer, referred to here as models (I) and (II), used to air condition homes of different sizes, are plotted below. Both units use refrigerant R410A. Table 1 gives the refrigeration capacity and power consumption values furnished by the manufacturer in 2008 at $T_{\text {in }} 27^{\circ} \mathrm{C}$ and $T_{\text {out }} 35^{\circ} \mathrm{C}$. The table differentiates among three load rates: minimum load (25\%), mean load (100\%) and maximum load (120\%). The manufacturer's values for AC unit performance at $T_{\text {in }} 25^{\circ} \mathrm{C}$ and a number of outdoor temperatures are shown in Table 2 for maximum loads (maximum 1.r.). The electric power value includes compressor and indoor and outdoor fan consumption.

From above tables and equations in Section 4, it can be concluded that:

Model (I) can accommodate the $4.9 \mathrm{~kW}$ load generated at $T_{\text {out }} 39^{\circ} \mathrm{C}$ in a home with $(U A)_{\mathrm{G}} 0.35 \mathrm{~kW} \mathrm{~K}^{-1}$ (the value assumed in the present study).

Model (II) can accommodate the $10.3 \mathrm{~kW}$ load generated at $T_{\text {out }} \quad 39^{\circ} \mathrm{C}$ in a home with $(U A)_{\mathrm{G}} \quad 0.79 \mathrm{~kW} \mathrm{~K}^{-1}$.

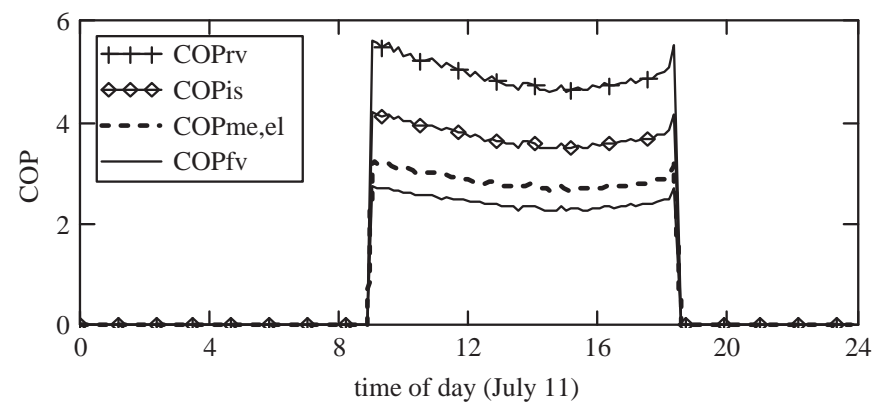

Fig. 10. Coefficients of performance on 11 July.

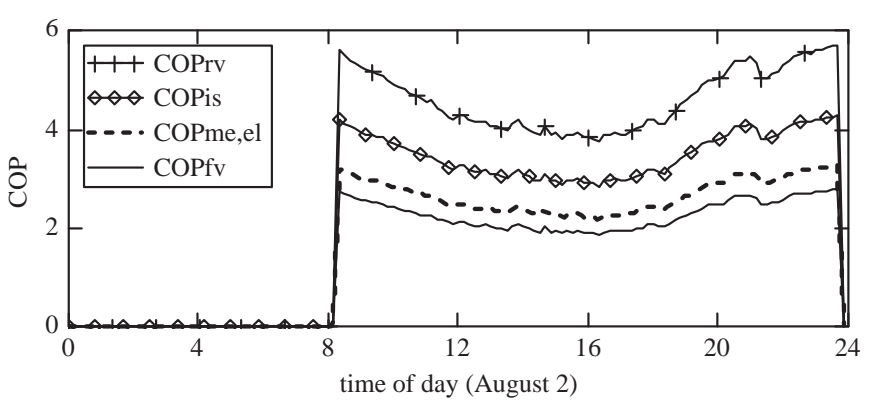

Fig. 11. Coefficients of performance on 2 August.

Figs. 13 and 14 show performance curves plotted with the manufacturer's data, supplemented with Tassou and Qureshi's experimental findings for air tight compressors [20]. These curves give the overall COP considering the effect of variable flow regu lation, at constant temperatures. When the outdoor temperature varies, i.e., under the usual conditions, efficiency adopts different values depending on the condensation temperature (or outdoor temperature). The result is a new floating pressure or temperature plot (dotted lines) that indicates the COP for the variable flow compressor.

Figs. 13 and 14 provide a method for determining the COP of a commercial unit $\left(\mathrm{COP}_{\mathrm{com}}\right)$ as a function of load rate. As seen, the peak cooling demand for a standard home can be met by model (I). Likewise, according to Fig. 6, the mean seasonal demand was 39\% of the peak demand, which for that unit implies a mean load rate of $46.8 \%$. Therefore, the approximate mean $\mathrm{COP}_{\text {com }}$ deduced from Fig. 13 was 3.5. In the case of model (II), used for buildings with higher cooling demand, the COP is observed to be slightly higher. However, as it fits in better with the selected standard home, model (I) will be used in the following discussion.

\section{Results and discussion}

\subsection{Electricity consumption}

From the thermal demand on the three representative days and the performance values found in Section 5, electricity consumption results were calculated and plotted in Fig. 15. The maximum values observed were $2.9 \mathrm{~kW}$ on 2 August, $1.4 \mathrm{~kW}$ on 11 July and $0.7 \mathrm{~kW}$ on 13 June. All these peaks were recorded between 1:00 and 4:00 p.m. The daily electricity consumption was $24.7 \mathrm{kWh}$ on 2 August, $10.2 \mathrm{kWh}$ on 11 July and $1.8 \mathrm{kWh}$ on 13 June. The value for the entire summer came to $919.9 \mathrm{kWh}$ per home. Note that the power consumption for AC was highest in July and August and very low in June and September.

On the other hand, the electricity consumed by the residential sector in the entire region of Madrid in the summer of 2008 was as

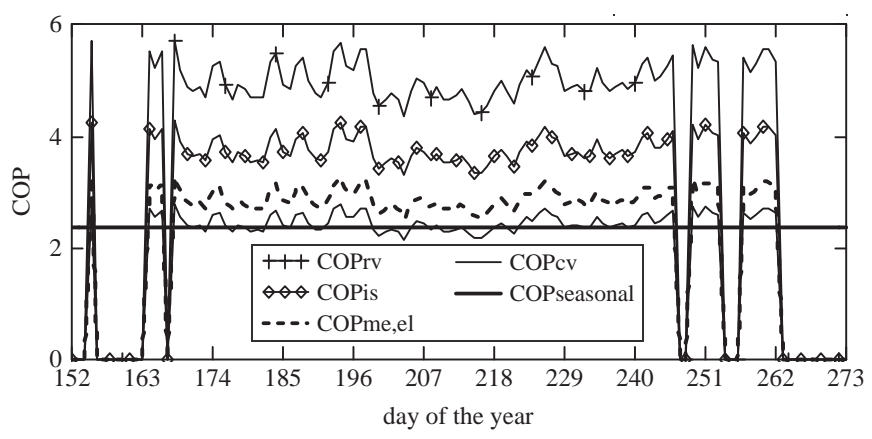

Fig. 12. COP for the entire summer. 
Table 1

AC unit performance at partial load based on manufacturer information $\left(T_{\text {in }} \quad 27^{\circ} \mathrm{C}\right.$ and $T_{\text {out }} 35^{\circ} \mathrm{C}$ ).

\begin{tabular}{llcc}
\hline Model (I) l.r. (\%) & Min. (25) & Mean (100) & Max. (120) \\
\hline$Q(\mathrm{~kW})$ & 1.35 & 5.27 & 6.33 \\
$W(\mathrm{~kW})$ & 0.48 & 1.64 & 2.37 \\
& & & \\
Model (II) l.r. (\%) & Min (15) & Mean (100) & Max (130) \\
$Q(\mathrm{~kW})$ & 1.46 & 10.55 & 14.07 \\
$W(\mathrm{~kW})$ & 0.60 & 3.28 & 4.80 \\
\hline
\end{tabular}

Table 2

AC unit performance at maximum load (based on manufacturer information).

\begin{tabular}{llrrrrr}
\hline & $T_{\text {out }}$ & $25^{\circ} \mathrm{C}$ & $32^{\circ} \mathrm{C}$ & $35^{\circ} \mathrm{C}$ & $40^{\circ} \mathrm{C}$ & $43{ }^{\circ} \mathrm{C}$ \\
\hline Model (I) & & & & & & \\
$\left(T_{\text {in }} 25^{\circ} \mathrm{C}\right)$ & $\mathrm{Q}_{\max }(\mathrm{kW})$ & 6.7 & 6.3 & 6.2 & 5.9 & 5.8 \\
& $W_{\max }(\mathrm{kW})$ & 1.9 & 2.3 & 2.4 & 2.5 & 2.6 \\
& & & & & & \\
Model (II) & & & & & & \\
$\left(T_{\text {in }} 25{ }^{\circ} \mathrm{C}\right)$ & $\mathrm{Q}_{\max }(\mathrm{kW})$ & 14.9 & 14.1 & 13.7 & 13.2 & 12.8 \\
& $W_{\max }(\mathrm{kW})$ & 3.9 & 4.6 & 4.8 & 5 & 4.7 \\
\hline
\end{tabular}

shown in Fig. 16. Consumption peaked on 19 July at $17 \times 10^{6} \mathrm{kWh}$, while the total electricity demand for AC homes throughout the summer was $617 \times 10^{6} \mathrm{kWh}$. When the calculation was performed for the mean $\mathrm{COP}_{\text {com, }}$ electricity consumption on 19 July was $10.8 \times 10^{6} \mathrm{kWh}$, while it came to $417 \times 10^{6} \mathrm{kWh}$ for the entire summer, which is $32.4 \%$ lower than found with the simulation. Table 3 summarises electricity consumption in the region of Madrid.

\subsection{Cost}

Since the price of residential electric power, including tax was $€ 0.17 / \mathrm{kWh}$ in Spain in 2008, and the AC season consisted of 100 days (from 12 June to 19 September), the total cost per home came to $€ 156$. As shown in Fig. 17, the mean daily cost was $€ 1.6$.

\subsection{Contribution of residential AC systems to total and peak electricity consumption}

Calculating the portion of electricity consumed in a city by residential $A C$ is not a straightforward procedure. In the present study, the effect of the outdoor temperature on electricity demand was assessed by analysing consumption in summer and identifying the days with maximum daily demand and the exact time when the characteristic value of "peak power consumption" was recorded. The used data of total electricity consumption corresponding to Madrid were furnished by the distribution utility Iberdrola Dis tribución S.A.U [6]. As this company supplies just $66 \%$ of the elec tricity consumed in the region, these data were extended to the

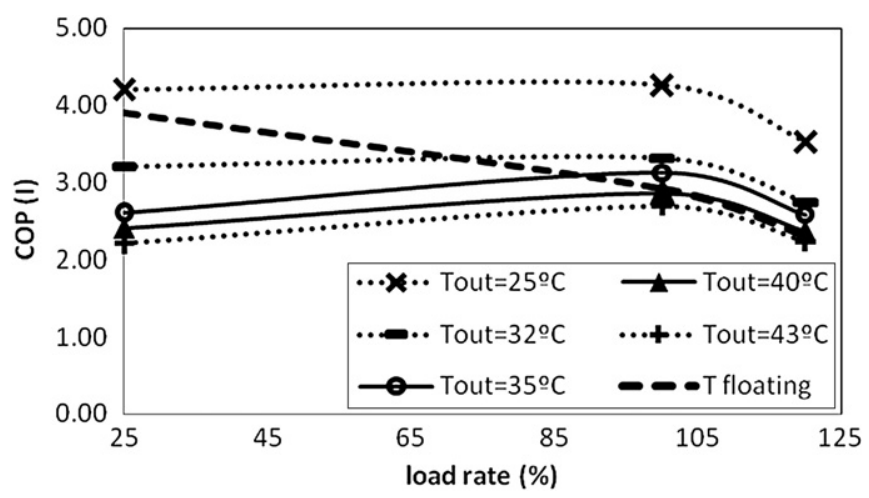

Fig. 13. Manufacturer's coefficient of performance (COP) for unit (I).

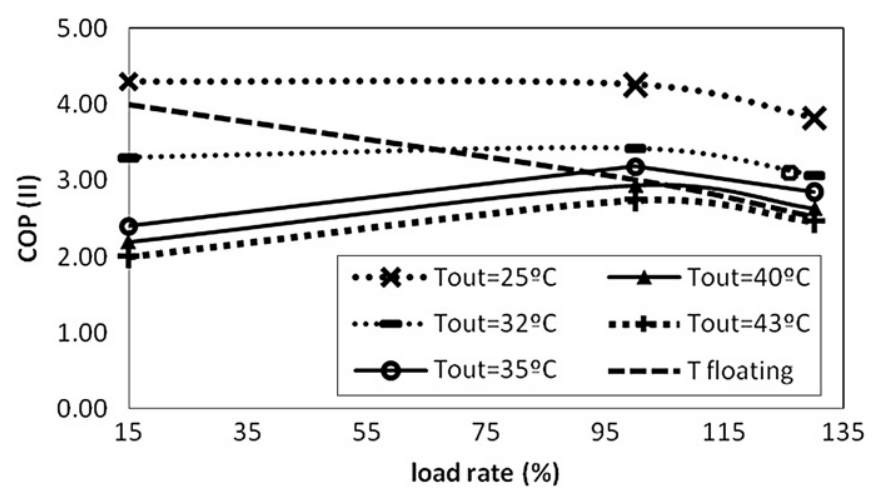

Fig. 14. Manufacturer's COP for unit (II).

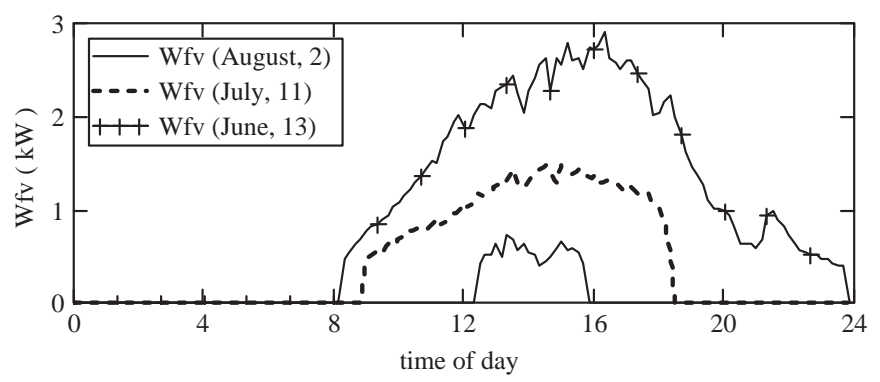

Fig. 15. Electricity consumption on three representative days.

whole region of Madrid. Table 4 shows some of those values, including residential, industrial and commercial consumption.

Total demand in the cooling season of 2008 (from 12 June to 19 September) came to $9161 \mathrm{GWh}$. The day when electricity demand was highest, at $100.5 \mathrm{MWh}$, was 30 June. This day, "peak power consumption" came to $5443 \mathrm{MW}$, with an outdoor temperature of $38.7^{\circ} \mathrm{C}$. The high temperature on 1 July was $38.3^{\circ} \mathrm{C}$, while the electricity demand was $99.98 \mathrm{MWh}$ and the "peak power consumption" $5282 \mathrm{MW}$. By contrast, on 5 August, with a high outdoor temperature of $40.4^{\circ} \mathrm{C}$, demand was $64.4 \mathrm{MWh}$ and "peak power consumption" $5202 \mathrm{MW}$. The reason why demand was lower than in June and July despite this higher outdoor temperature was that commercial and industrial consumption declined as a result of seasonal shop closures and personnel holidays in other types of businesses. "Peak power consumption", in turn, was approximately the same as in July and somewhat lower than in June.

According to the simulation results given in Table 3, the elec tricity consumed by AC units accounted for approximately $6.7 \%$ of the total consumption in the region.

The maximum "peak power consumption" for the summer, $5.44 \times 10^{6} \mathrm{~kW}$, was recorded at 4:00 p.m. on 30 June, which did not concur with maximum daily residential demand (Fig. 16). Fig. 18 shows the electricity consumption per home on that day, when daily demand was $16.4 \mathrm{kWh}$.

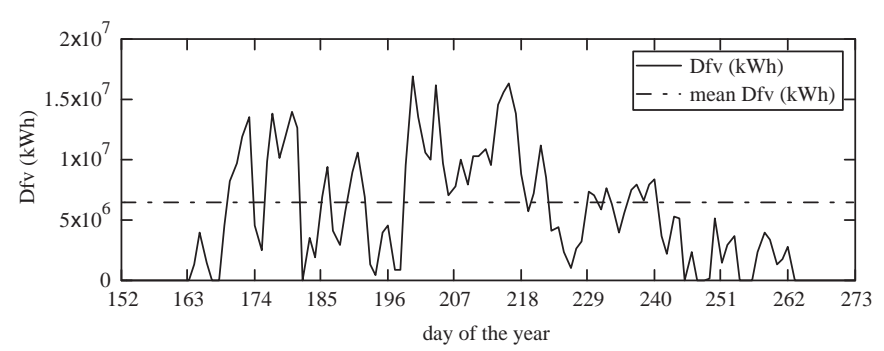

Fig. 16. Electricity consumed by residential AC in the region of Madrid in the summer of 2008 . 
Table 3

Peak and seasonal electricity demand.

\begin{tabular}{lll}
\hline Peak electric consumption per home (19 July 2008) & 5.78 & $\mathrm{~kW}$ \\
Electric power demand in the region (19 July 2008) & $17 \times 10^{6}$ & $\mathrm{kWh}$ \\
Seasonal electric power demand per home & 920 & $\mathrm{kWh}$ \\
Seasonal electric power demand in the region & $617 \times 10^{6}$ & $\mathrm{kWh}$ \\
\hline
\end{tabular}

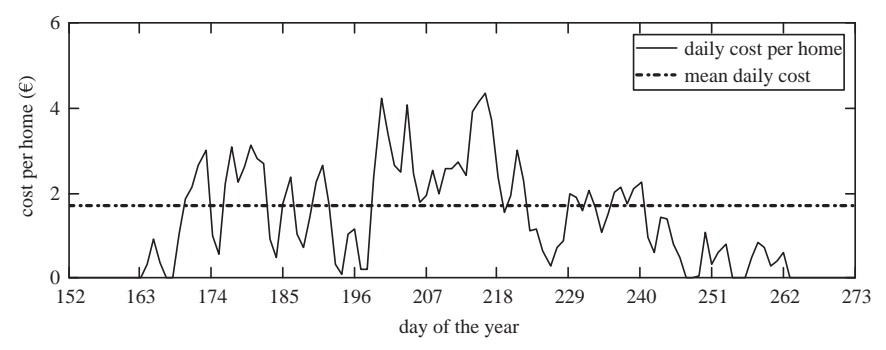

Fig. 17. Seasonal cooling cost per home.

AC units operated from 9:00 a.m. to 8:30 p.m., with two consumption peaks at around 4:00 p.m. The highest was $2.34 \mathrm{~kW}$ and happened at 4:15. Taking the number of families on holiday outside Madrid into consideration, the units in operation at that time consumed around $1.79 \times 10^{6} \mathrm{~kW}$. Consequently, AC units in residential buildings accounted for $33 \%$ of the "maximum peak consumption" in the region of Madrid in the summer of 2008.

When the calculation was performed using the $\mathrm{COP}_{\text {com }}$ obtained in Section 6, the "peak consumption" for the units operating at that time was $1.08 \times 10^{7} \mathrm{~kW}$, or just $19.8 \%$ of the "maximum peak consumption" for the summer.

\section{Environmental impact}

The environmental impact of the refrigerants used in AC units and the emissions generated in electric power production is eval uated below. The parameter used for this purpose is the Total Equivalent Warming Impact (TEWI), which represents the amount of associated $\mathrm{CO}_{2}$.

To begin with, TEWI can be broken down into two parts. The first, GWP (Global Warming Potential), takes account of the refrigerants that leak directly into the air, while the second, IGWP (Indirect Global Warming Potential), refers to the emissions attributable to the generation of electricity needed to power AC systems.

As Eq. (27) indicates, GWP depends on the age of the AC facility in years $(Y)$, the refrigerant mass in the chiller $\left(M_{\mathrm{r}}, \mathrm{kg}\right)$ and the yearly leakage rate $(f)$, according to Menzer $[23,24]$. Given that each residential unit contains about $1.5 \mathrm{~kg}$ of refrigerant, the total mass of refrigerant inside the units in the whole region of Madrid comes to $1.275 \times 10^{6} \mathrm{~kg}$.

Refrigerant leakage $f \cdot M_{\mathrm{r}} \cdot Y$

Table 4

Electricity consumption in Madrid on selected days in 2008.

\begin{tabular}{llcl}
\hline & & Daily (MWh) & Hourly peak (MW) \\
\hline 4 May & Sunday & 62.74 & 3281 \\
5 May & Monday & 83.10 & 4318 \\
29 June & Sunday & 77.45 & 3887 \\
30 June & Monday & 100.46 & 5443 \\
1 July & Tuesday & 99.98 & 5282 \\
21 July & Monday & 97.53 & 5281 \\
3 August & Sunday & 49.58 & 3749 \\
5 August & Tuesday & 64.39 & 5202 \\
2 September & Tuesday & 89.62 & 4798 \\
15 October & Wednesday & 83.81 & 4331 \\
\hline
\end{tabular}

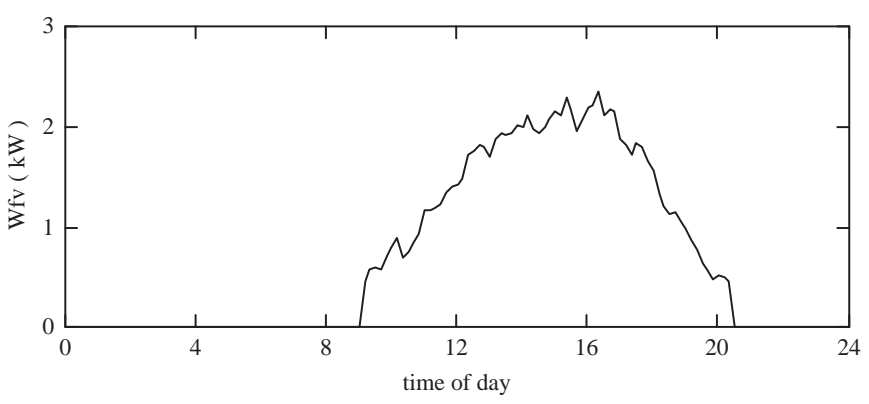

Fig. 18. Electric power consumption per home on the day of maximum peak power consumption (30 June).

One possible reference for the value of the leakage rate $(f)$ is the Japanese Ministry of Economy, Trade and Industry (METI), which computed fluorinated refrigerant leaks in 2008 in that country to be 10 times higher than forecast in 2007. The difference was attributed to the inclusion in the latter figure of losses due to breakdowns and repairs, a circumstance taken into consideration in the present exercise. The annual leakage rate for household air conditioners was revised upwards from $0.2 \%$ in 2007 to $2 \%$ in 2008 ; for chilling units from 2 to $6 \%$ and for medium sized refrigeration units from $1.1 \%$ to $17 \%$.

The entire $1.5 \mathrm{~kg}$ charge of refrigerant might be expected to leak out of an AC unit during its 20 year service life, in addition to a further $1.5 \mathrm{~kg}$ as a result of breakdown and repair. At the end of that period, $50 \%$ of the initial charge, or $0.75 \mathrm{~kg}$, might be recovered for storage in the refrigerant banks envisaged in the F gas Regula tion. Further to these assumptions, $2.25 \mathrm{~kg}$ of refrigerant would leak into the atmosphere in 20 years' time, i.e., at a rate of $0.112 \mathrm{~kg}$ or $5 \%$ per year, which is consistent with the findings published by the METI [25]. Given the 20 year GWP (3400) (Solvay Fluor Solkane Catalog, 2006 [26]), the TEWI for the region of Madrid would come to approximately $325 \times 10^{3} \mathrm{tCO}_{2} /$ year.

In 2008, according to the Spanish Ministry of the Environment and Rural and Marine Affairs [1], about $0.4 \mathrm{~kg} \mathrm{CO}$ are emitted per $\mathrm{KWh}$ of electricity generated in Spain. Consequently, the impact of IGWP or indirect emissions was around $247 \times 10^{3} \mathrm{t} \mathrm{CO}_{2}$. Finally, the sum of GWP and IGWP, i.e., TEWI, was $572 \times 10^{3} \mathrm{t} \mathrm{CO}_{2}$.

\section{Conclusions}

AC unit efficiency under different outdoor conditions is an important consideration, for it provides insight into the optimal capacity to be installed and the effect on demand of connecting AC at one or another outdoor temperature.

The demand for electricity in Madrid generated by residential AC was calculated on the basis of data from the Spanish National Statistics Institute and an analysis of the thermodynamic AC cycle. This calculation was performed via numerical simulation, using temperatures recorded during the summer. In the intermediate steps, thermal demand, the COP for AC units, summer peaks, and maximum daily and seasonal demand were also found. Finally, the environmental impact of the polluting emissions was evaluated.

Mean electricity demand per household in the summer of 2008 was $920 \mathrm{kWh}$. Maximum and mean daily expenditure came to $€ 4.4$ and $€ 1.6$, respectively, while the total expenditure for the season was $€ 156$.

The maximum daily demand attributable to AC in Madrid was $17 \times 10^{6} \mathrm{kWh}$, while the seasonal value reached $617 \times 10^{6} \mathrm{kWh}$. Such electricity consumption implies the emission of around $572 \times 10^{3}$ $\mathrm{TOE} \mathrm{CO}_{2}$. Taking into account the total electricity consumption of the whole region, it was found that AC accounted for approximately $6.7 \%$ of the total electricity demand in during summer. 
Due to the impact of holiday travel, peak consumption of elec tricity in Madrid was not recorded on the days with the highest temperature. In 2008, maximum "peak consumption" was observed on 30 June, when the outdoor temperature was $38.7^{\circ} \mathrm{C}$. Residential AC was observed to account for approximately $33 \%$ of the "maximum peak consumption". However, when the calcula tions were performed with the commercial efficiency values fur nished by manufacturers, that value declined to $19.8 \%$. Likewise, electricity demand due to residential AC was 32\% lower than obtained with the method used in the present study.

\section{Acknowledgements}

This study was funded by the Spanish Ministry of Science and Innovation under Projects INVISO, sub project SP3 "Sustainable power generation in housing" and ENE2010 20650 C02 01. Author A. Gonzalez Gil is grateful to the Spanish National Research Council (CSIC) for its support while he worked toward his PhD. The authors also wish to thank J. Cabetas from Iberdrola de Distribución Eléc trica S.A.U. for the information furnished.

\section{References}

[1] Ministerio de Medio Ambiente y Medio Rural y Marino (MARM). Inventario de Gases de Efecto Invernadero de España. MARM; 2010.

[2] Comunidad de Madrid. Plan Energético de la Comunidad de Madrid 2004 2012. Comunidad de Madrid; 2005.

[3] Red Eléctrica de España. Informe del sistema eléctrico español en 2008. Red Eléctrica de España; 2009.

[4] Psiloglou BE, Giannakopoulos C, Majithia S, Petrakis M. Factors affecting electricity demand in Athens, Greece and London, UK: a comparative assessment. Energy; 2009:1855 63.

[5] Instituto Nacional de Estadística, www.ine.es; 2010.
[6] Iberdrola Distribución Eléctrica S.A.U. Personal communication.

[7] Ministerio de la Vivienda, www.mviv.es; 2009.

[8] Izquierdo M, Lizarte R, Marcos JD, Gutiérrez G. Air conditioning using an aircooled single effect lithium bromide absorption chiller: results of a trial conducted in Madrid in August 2005. Appl Therm Eng; 2008:1074 81.

[9] Ministerio de Industria, Turismo y Comercio. Reglamento de Instalaciones Térmicas en Edificios (RITE). Ministerio de Industria, Turismo y Comercio; 2007.

[10] Pizzetti C. Acondicionamiento del aire y refrigeración. Teoría y cálculo de las instalaciones. 2nd ed. Madrid: Bellisco; 1991.

[11] ASHRAE. ASHRAE handbook-fundamentals. Atlanta: ASHRAE; 2009

[12] Ministerio de Vivienda. Código Técnico de la Edificación; 2006.

[13] Barómetro Municipal de Consumo. Madrid, $2^{\circ}$ cuatrimestre de 2008.

[14] Asociación de Fabricantes de Equipos de Climatización, AFEC, http://www. afec.es/es/mercado-2009.asp; 2010.

[15] Yu FW, Chan KT. Experimental determination of the energy efficiency of an air-cooled chiller under part load conditions. Energy; 2005:1747 58.

[16] Bernier J. La pompe de Chaleur: Mode d'emploi. Paris: PYC Editions; 1979.

[17] Chen Yu, Halm NP, Braun JE, Eckhard AG. Mathematical modeling of scroll compressor part II: overall scroll compressor modeling. Int J Refrigeration; 2002:751 64 .

[18] Qureshi TQ Tassou SA. Variable speed capacity control in refrigeration system. Appl Therm Eng; 1996:103 13.

[19] Shao S, Shi W, Li X, Chen H. Performance representation of variable-speed compressor for inverter air conditioners based on experimental data. Int J Refrigeration; 2004:805 15.

[20] Tassou SA, Qureshi TQ. Comparative performance evaluation of positive displacement compressors in variable- speed refrigeration applications. Int J Refrigeration; 1998:29 41

[21] Aprea C, Mastrullo R, Renno C. Experimental analysis of the scroll compressor performances varying its speed. Appl Therm Eng; 2006:983 92.

[22] Danfoss. Datasheet, technical data maneurop reciprocating compressor type MTZ050-5; 2008

[23] Menzer MS, Hourahan GC. Air conditioning and refrigeration's contribution to global warming gases. In: Proceedings of the international CFC and halons alternatives conference, Washington DC; 1995.

[24] Menzer MS. Responsible use guide for minimizing fluorocarbon emissions in manufacturing facilities, vol. 3. ARI; 2007.

[25] International Institute of Refrigeration. Briefs. Japan: refrigerant leakage larger than expected. IIR Newslett July 2009;39.

[26] Solvay Fluor Solkane Catalog; 2006. 